\title{
Imagens que pensam, que sonham, que sentem. Uma proposta ousada?
}

\author{
Adriana Tulio Baggio
}

SAMAIN, E. (Org.).

Como pensam as imagens.

Campinas: Editora da Unicamp, 2012

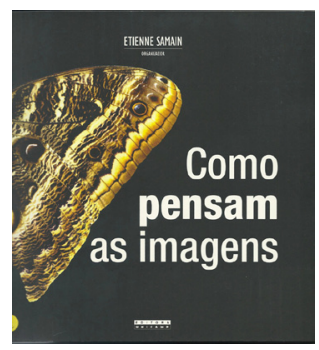

Resumo: As imagens podem pensar, de maneira independente, como se fossem sujeitos? Para apresentar e discutir essa ideia, Etienne Samain reuniu textos próprios e de mais nove autores. Inspirados pelos conceitos de Aby Warburg, Gregory Bateson e Didi-Huberman, os artigos tratam de uma teoria da imagem e sua operação metodológica e analítica, especialmente em relação à fotografia. Os textos estão organizados em três partes e se complementam, dialogam e até mesmo se opõem, formando um panorama rico e consistente de outra proposta epistemológica da comunicação.

Palavras-chave: imagem; fotografia; epistemologia da comunicação

Abstract: Images that think, that dream, that feel. A bold proposal? - Are images independently sentient, like individuals? To present and discuss this idea, Etienne Samain put together a collection of his own texts and those of nine other authors. Inspired by the concepts of Aby Warburg, Gregory Bateson and Didi-Huberman, these articles discuss an image theory and its methodological and analytical operation, particularly with regard to photography. Organized in three parts, the texts complement, dialogue and even differ from each other, creating a rich and consistent panorama of a another epistemological proposal of communication.

Keywords: image; photography; epistemology of communication 
Recebo o livro organizado por Etienne Samain e me encanta a capa ilustrada por uma borboleta. O título é instigante, mas a fotografia suga primeiro a atenção. Vejo olhos de coruja nas asas do inseto e, talvez, a cabeça de uma serpente na extremidade dessas asas. Sensação de beleza e perigo.

Abro o livro. Abandono as explorações do imaginário e envolvo-me com o aspecto racional. Dizer que as imagens pensam - ao contrário de dizer que nos fazem pensar - sugere um caráter de autonomia, de independência, de livre-arbítrio. É como se as imagens tivessem vida própria, como se fossem sujeitos, e não produtos. Seria isso que o organizador quis dizer? Ou trata-se de uma prosopopeia, de um recurso estilístico para nos lembrar a importância das imagens em nossa cultura?

Já nos agradecimentos e na apresentação, Samain revela a inspiração teórica dos textos incluídos no livro: Gregory Bateson, "que concebe a comunicação humana tanto como um fato cultural quanto como uma orquestração ritual, sensível e sensorial, sempre inserida num contexto", e Aby Warburg, que "exuma e reaviva, nas obras de arte e outros grandes movimentos da história, as 'formas [fórmulas] de patético', presentes em todas as culturas humanas" (p. 14).

É da articulação e da empatia entre as ideias desses "dois gigantes" que surge, para Samain, a questão de como pensam as imagens. O teólogo, antropólogo, fotógrafo e professor da pós-graduação em multimeios da Unicamp, belga radicado no Brasil, propõe que as imagens nos fazem pensar porque, ao se associarem, tornam-se portadoras de pensamento, constituem-se em formas que pensam. Ver as imagens dessa maneira seria, assim, uma forma de "reavaliar [...] a epistemologia da comunicação, ameaçada na dubitável matriz logocêntrica de nosso Ocidente" (p. 17).

Os onze capítulos do livro estão divididos em três partes: Pensar por imagens traz textos que exploram a questão epistemológica central, com base nas propostas de Bateson, Warburg e Didi-Huberman; Quando ardem as imagens agrupa artigos que falam sobre imagens consumidas, reavivadas por um sopro - da memória, da articulação com a fala, da associação com outras imagens. São trabalhos em que é possível perceber a operação da epistemologia das imagens pensantes sobre objetos como fotografias de família e artísticas; a terceira parte mostra a Cumplicidade das imagens. Nesse último conjunto, os textos propõem "percursos críticos entre 'modo de ver' e 'modo de pensar', o que as matrizes comunicacionais buscam nos oferecer na atualidade" (p. 16). Um caderno em papel cuchê, no final do livro, traz reproduções coloridas das imagens impressas em preto e branco que ilustram os artigos.

\section{As imagens que pensam}

Além de organizar o livro, Etienne Samain assina dois de seus artigos, ambos na primeira parte. Em "As imagens não são bolas de sinuca. Como pensam as imagens", 
o autor enxerga as imagens como coisas vivas. É nesse texto que Samain defende a ideia de imagens pensantes, a partir de três argumentos: de que toda imagem nos oferece algo para pensar, seja ligado ao real, seja ligado ao imaginário; de que as imagens são portadoras de pensamentos porque veiculam pensamentos de quem as produziu e incorporam pensamentos daqueles que as observaram (conceito aprofundado e bem exemplificado por Jorge Coli, em outro texto integrante da primeira parte), configurando-se como um lugar de memória coletiva; e de que as imagens são formas que pensam, dialogam e se comunicam, independentemente de nós.

Já em "Aby Warburg. Mnemosyne. Constelação de culturas e ampulheta de memórias", Etienne Samain apresenta o historiador, o contexto em que viveu e também sua obra: o atlas de imagens Mnemosyne, "uma 'história de arte sem palavras' ou, ainda, uma 'história de fantasmas para pessoas adultas'" (p. 52).

Mnemosyne consiste em um conjunto de 79 painéis de fundo preto sobre os quais Warburg distribuiu aproximadamente novecentas imagens - fotografias em p\&b, em sua maior parte, retiradas de um arquivo de mais 25 mil exemplares. $\mathrm{O}$ trabalho começou em 1924 e foi interrompido com a sua morte, em 1929. Warburg organizava as imagens nos painéis de forma que pudessem dialogar com as demais e todas entre si. É a partir da constituição desses painéis que emergem dois importantes conceitos: Pathosformeln (forma ou fórmula do patético) e Nachleben (o "após-viver" ou "supervivência"). De maneira bastante superficial: as formas do patético se referem às emoções profundas do ser humano, como o medo, o terror, a paixão, a sedução, a felicidade, enquanto as supervivências são as imagens do patético humano. Imagens que "se pensam e dialogam no tempo", mas não em uma linearidade histórica; elas "abrem e desdobram a história, a descobrem ou a encobrem, a reencontram e a ressuscitam, a fazem viver e existir" ( $p$. 58). Esses conceitos ficam mais claros a partir do relato das experiências de Warburg no território dos índios Hopi, no Novo México (EUA), no final do século XIX. Warburg observou o ritual no qual os índios comparavam a serpente a um raio. O fundamento do ritual está em que, ao domar a perigosa serpente - algo que os índios podem fazer -, seria possível controlar o raio - incontrolável. Para esses índios, o raio que corta o céu é a serpente que foge: ambos são o perigo, o terror, e assumem a mesma forma de ziguezague quando em movimento.

O alerta para a ousadia de sua proposta, que Samain expõe na apresentação do livro, é retomado quando o autor exercita suas próprias referências a outras imagens de "formas do patético": as placas de trânsito que anunciam um trecho sinuoso e perigoso da estrada, o sinal telegráfico de perigo SOS - duas serpentes prontas a dar o bote ladeando outra serpente, enrolada -, a serpente de Esculápio, que simboliza a medicina e a farmácia, as serpentes de Laocoon, a serpente do Éden.

Quando cheguei a esse ponto do livro, lembrei da sensação que tive ao pensar ter visto uma cabeça de serpente nas asas da borboleta que ilustra a capa. Será que, então, 
eu mesma não estaria entendendo as imagens a partir do que pretendia Warburg? Por uma lógica do sensível, do sensorial e do imaginário, em adição (e sem se opor) à lógica da razão?

Esta primeira parte traz ainda um breve artigo em que Sylvain Maresca propõe que as imagens, especialmente a fotografia, não dizem nada. A princípio, parece que Maresca contradiz o pensar das imagens. No entanto, o autor ressalta que as imagens não são mudas. Elas não falam porque não querem, são "múticas": prescindem das legendas, das explicações e dos significados. Quando são definidas por eles, é como se se apagassem. Maresca pede que não se encontrem significados tão rapidamente, que não se interpretem as fotografias tão imediatamente. Para ele, o fotógrafo deve procurar ver sem saber, ver mais de perto, descrever sem logo interpretar e aceitar a heterogeneidade das coisas.

Já falamos antes sobre a ideia de que as imagens trazem não só o pensamento de quem as produziu, mas também daqueles que as olharam. Jorge Coli diz, em "A obra ausente", que as obras de arte se constituem como tal pela percepção de quem as observa, e ainda por sua inserção no "tecido mais amplo" de outras obras, da realidade e da memória. Problematizando a famosa questão de Walter Benjamin, também fazem parte da obra as suas reproduções, imitações e paródias. Para Jorge Coli, em alinhamento às ideias de Warburg, tais associações se dão pela forma.

No último texto da primeira parte, Marie-Anne Lescourret mostra como a tensão entre apolíneo e dionisíaco, razão e sentimento, inteligível e irracional, própria do pensamento de Warburg, aparece também nas ciências históricas. Lescourret enxerga nas concepções das Escolas dos Anais o dionisíaco em tensão com o apolíneo da história positivista. O reflexo dessa concepção é a rejeição de Warburg à visão da história da arte como uma sucessão de escolas. No lugar das relações lineares, temporais, geográficas e formais das escolas, propõe-se uma aproximação sensível e antropológica das obras artísticas.

\section{As imagens que sentem e sonham}

Dos três trabalhos da segunda parte, dois mostram como pensam (ou sentem?) aquelas imagens envolvidas por ternura e afeto: as fotografias de família. "Uma antropologia das 'supervivências': as fotobiografias", de Fabiana Bruno, é exemplar, além de outros motivos, por apresentar claramente uma metodologia de pesquisa desse tipo de imagem. Se no trabalho de Bruno as imagens "sentem", em "Uma foto familiar: aprisco de emoções e pensamentos (Anotações delirantes sobre [a]sombrografia)" a fotografia da família de Eduardo Peñuela Cañizal está entre aquelas que "sonham". Ao observar a imagem de seus pais e irmãos, o autor percebe que "o inconsciente ótico se apresenta como artifício capaz de efetuar a transformação do latente em manifesto" (p. 122).

O terceiro artigo, de Ronaldo Entler, fala sobre as lacunas e os silêncios que compõem as imagens. Retomando as concepções de textos anteriores, como os de Semain e Coli, Entler diz: 
Se a imagem é um lugar de articulações, ela é também um lugar de conflitos: nela se cruzam autores, uma sociedade, um momento histórico, uma técnica, o objeto de representação e tantos outros olhares dedicados a ela ao longo do tempo e, assim, outras sociedades etc., coisas que não são necessariamente solidárias entre si na produção de um sentido comum (p. 133).

\section{As imagens que nos fazem ver de outro modo}

$\mathrm{Na}$ terceira parte do livro, três textos apresentam outras maneiras de pensar as imagens que pensam, no sentido de sua autonomia e de seu papel de sujeito de ações no mundo. Helouise Costa, em "Surpresas da objetiva: novos modos de ver nas revistas ilustradas modernas", lança suspeitas sobre a aparentemente inocente relação entre os preceitos da nova visão, manifestação de uma proposta fotográfica de vanguarda, e o papel de "pedagogas do olhar" assumido pelas revistas ilustradas da primeira metade do século XX. Com exemplos de fotografias jornalísticas e publicitárias retiradas das revistas Life, Vu e O Cruzeiro, Costa defende que a nova visão proposta por essas publicações não pode ser considerada exatamente uma pedagogia, devido à falta do aspecto crítico que seria inerente aos processos pedagógicos. A estetização e o inusitado das fotografias da nova visão "deixavam de fazer o observador pensar sobre o mundo e passavam a fazê-lo pensar sobre elas próprias" (p. 168). Passa-se do objetivo de alienação - quando do uso desse tipo de estética pelas imagens da propaganda política soviética - para o objetivo de sedução para o consumo.

Tal crítica à pretensa pedagogia do olhar suscitada pelas imagens da nova visão não aparecem no artigo de Annateresa Fabris - "Uma sensação estranha, que faz pensar" -, talvez porque a autora fale de imagens artísticas, e não da apropriação da estética para o uso no jornalismo e na publicidade (porém, seria fácil discernir claramente tais limites?). O texto mostra a relação entre as categorias estabelecidas por Lászlo Moholy-Nagy e as duas grandes áreas de atuação da fotografia propostas por Thomaz Farkas na revista Íris, em 1948. Fabris vai discorrer sobre como tais preceitos conduziram as discussões sobre fotografia, influenciando fotógrafos brasileiros (ou que atuavam no país) na busca por desestabilizar a percepção corriqueira, estimulando o pensamento por meio do estranhamento.

O último artigo, de Kati Caetano, revela como o pensar das imagens se insere nos caminhos teóricos trilhados pela autora. Como pregnantes de qualidades sensíveis, as imagens nos fazem chegar ao cognitivo pelo estésico, quando nos suscitam emoções. "O espectador integrado: modos de figuração da fotografia" fala do acaso como fonte destinadora de sentido a partir da interação do sujeito com a fotografia.

A ideia de "imprevisibilidade acidental" é analisada a partir de três práticas fotográficas: a estética do instante decisivo, de Cartier-Bresson, a estética do "isso foi atuado", de François Soulages, e a "fotografia pós-moderna", de Dominique Baqué. Com base 
em exemplos em que o espectador "entra" na imagem, ou quando exterior e interior se confundem nela, Caetano desconstrói a ideia da fotografia como sendo puramente visual. Os sentidos das imagens, além de não serem previamente dados, são apreendidos pelo sentir com os demais sentidos.

Quem vê nesse último postulado a influência de um pensar sociossemiótico sobre as três práticas fotográficas não se engana. O estudioso dessa teoria vai reconhecer seus pressupostos no percurso trilhado por Kati Caetano em suas reflexões, por meio de marcas óbvias e outras mais sutis - um bônus para o leitor, que terá a oportunidade de apreender a ciência e uma das formas de sua metodologia no momento em que frui de sua operação.

\section{Para concluir}

Está claro que fui atraída pelas ideias propostas nos textos desse livro. No entanto, visto que Samain faz mais de um alerta para a ousadia das suas propostas, talvez esteja se preparando para os questionamentos daqueles que encaram a apreensão do cognitivo pelo sensível como uma forma de "impressionismo", desvalorizando e até mesmo desqualificando as interpretações oriundas desse tipo de abordagem. Se ele estiver certo e o leitor vier a pensar dessa forma, não será, no entanto, pela falta de consistência, coerência ou articulação dos onze capítulos que compõem a coletânea. Tratando da teoria, da metodologia, apresentando sua operação em diferentes objetos ou mostrando o diálogo com outras linhas de pensamento, os textos oferecem uma abordagem bastante pertinente para os estudos, por exemplo, das imagens da imprensa e da publicidade. Essa última, especialmente, se ressente mais de uma certa falta de referências próprias da epistemologia da comunicação. Não seria esse pensar das imagens outra possibilidade epistemológica válida?

Adriana Tulio Baggio é doutoranda do Programa de Estudos Pós-Graduados em Comunicação e Semiótica (PEPG-COS) e pesquisadora do Centro de Pesquisas Sociossemióticas (CPS) da Pontifícia Universidade Católica de São Paulo (PUC-SP).

atbaggio@gmail.com 